$\star$ Rhizomes: Cultural Studies in Emerging Knowledge: Issue 32 (2017)

\title{
Byung-Chul Han, In the Swarm: Digital Prospects
}

\section{Review by Laura M. Ivey}

Byung-Chul Han, In the Swarm: Digital Prospects. Translated by Erik Butler. Cambridge, MA: The MIT Press, 2017.

Are the voices produced by digital communication so numerous today that they are now a roar of indecipherable noise? Are the images offered by digital communication such a simulation of reality that they are replacing reality and destroying our tactility? German philosopher Byung-Chul Han considers these ideas in In the Swarm: Digital Prospects, as he takes on the consequences of the constant flow of mediated communications and digital images. Han's latest installment in MIT Press's Untimely Meditation book series is the English translation of a previouslypublished 2013 German collection of essays, but the content is relevant and intriguing as Han develops cautionary narratives around the social impact of the digital world.

Sixteen chapters, which read like a series of essays, are tightly-packed into an 80-page book and contain provocative titles as "Outrage Society" and "Clever Hans." Instead of presenting his theses and providing evidentiary support, the author develops his main ideas in these chapters where sequence seems unimportant and all ideas are of equal gravity. Outrage Society, for example, ironically spans less than two pages and describes the problem of accessing an immediate digital outlet with a quick, emotional response. His observations in many parts of the book are Tweet-worthy in length, but he cleverly strings them together and delivers them cumulatively in a narrative, dinner-party-talk style. His conclusions are now four years old, an eternity in the digital world, but the effects Han suggests could take years to present and are still relevant.

Han opens with the chapter No Respect as a framework to explain what has been lost to the digital frenzy he terms "the shitstorm." Respect is looking back "with consideration and caution," and requires space between the observer and observed. This space, the one that separates private from public, and leaves room for respect, is being shrunken by social media as no private moments or matters are off-limits for digital distribution. Our private spaces are becoming nonexistent, with the most intimate details of personal lives being shared globally online, and where we exist only as in image.

Han recognizes that a large online community may seem, on the surface, to be an influential group but he argues that this new mass of people, a "digital swarm," has no real power because it has no ability to mobilize. One of Han's most vivid images is of the group of individuals represented by digital culture - this group has no spirit, no "we." Our incessant narcissism and self-interest is propelling us to be more individualistic, and an online forum allows gathering without actual assembly. Without coherence, there is no voice to the swarm - only noise. When individuals become outraged, there is no space to decompress before the communication is created and sent, and because the swarm can't mobilize, the outrage is usually self-serving instead of altruistic. Occasionally, when human individuals in the digital swarm do unite in person, their actions are not unified, but resemble those of animals who do swarm, "fleeting and unstable." Keeping in mind the original release date of 2013, recent political events have challenged this point and participants in marches worldwide would disagree with Han. Individually, Homo digitalis is part of the digital swarm, and can alternately maintain anonymity through screen names or avatars and a personal identity with a thoughtfully curated online profile, an "anonymous somebody." Although Han provides no direct evidence or examples to support these descriptions of the digital swarm, his imagery is relatable and resonates with anyone who has been part of an online community and has experienced such exchanges. 
The diminished personal and mental space has facilitated a society of individuals increasingly isolated from each other, and ultimately from the real. We have traded our solidarity for solitude, much like Sherry Turkle's observations in Alone Together.

In the chapter Demediatization, Plato casts a shadow when Han describes how online platforms are equalizers where anyone can create and share content. It is in the process of "abolishing all the priestly classes" which "spells trouble for representative democracy." Han advocates for leaders to have space to think, to float ideas, to work through difficult strategies without the immediate outrage and input from the public. Political strategy requires a measure of withholding information, which is contrary to what the swarm will allow. Individuals in the digital swarm want to represent themselves and their opinions without the use of a representative/middleman/politician.

Clever Hans is a chapter name and, as you know, the name of a horse who allegedly could count via a hoof-tap, but was later discovered only to be responding to unintentional cues from humans. It is Han's example of how communication is comprised of very little actual verbiage but many physical manifestations. Whether or not Clever Hans is a sly nod to clever Han's ideas is something only the author himself could confirm. Han agrees with Greek philosophers that communication includes both words and speaking style: rhetoric. The value of communication far surpasses the worth of the words. Hans asserts that we are becoming removed from actual humans because of our digital devices, therefore we are missing physical cues such as blinks or breaths, and the crackle of tension in a room. Han maintains we are losing our "tactility," but since Han is not a digital native himself, it is difficult to place his perceptions in context on this issue. Are digital natives less tactile? Han also asserts that we are losing the ability to gaze, not as a voyeur but as one who exchanges understanding with another, and ultimately to experience desire and love, which he speaks to 2017's The Agony of Eros. Are we so self-consumed that we are not capable of recognizing the Other? Can we love no one but ourselves? The respect that Han speaks of is related to this contemplative gaze, and he takes care to note that respect is different from a spectacle. Although no direct reference is made to The Society of the Spectacle by Guy Debord, it is impossible not to draw parallels, particularly the possibility that our reality is being replaced by digital imagery.

Heidegger's earth imagery is used to complete Han's analogy of a farmer versus a hunter. Han mourns the lack of cultivation and tending of information like his farmer example, which he perceives as being related to the earth, and authentic. Han advocates this farm-to-table model of information-gathering instead of the new digital model of predatory hunting, where information is stalked and gathered from numerous sources. Han misses an opportunity to explore Heidegger in other ways, such as his theories of enframing and threat of technology. Han and Heidegger appear to be on the same page regarding the unveiling of the truth as a process, but it is not fully explored here.

In Flight Into The Image, Han directly takes on digital images. Have our digital images become more real than our reality? Do they comprise a new reality? He employs the term "iconic reversal" to describe images that are so appealing that they are better than reality, to the point that reality can be disappointing. Han recognizes that we are in a struggle to understand what is real, when so much of the world around us has been digitally created. He uses the impact of time as a measuring benchmark for determining realness. "Digital is timeless. Analog suffers from time." "The digital does not blossom or gleam." Real things being time-worn recalls a scratchy movie on film, or even The Velveteen Rabbit, which makes for compelling reading. He argues that the digital is "less real" than the analog.

Our achievement society, as part of our capitalist system, means that we have become "perpetrator and victim in one" as we end up exploiting ourselves as a result of our self-centric goals. Han has addressed this phenomenon in detail in 2015's The Burnout Society. Digital availability means that work never leaves us, and exposure to endless positive messages online means that we are in an endless pursuit of achievement. In line with his thinking that the swarm is incapable of mobilizing for action, he says "burnout and revolution are mutually exclusive."

Information does not equal truth. Transparency does not equal truth. We might think that truth can be found through information and transparency in a digital environment, where every interaction is researchable and traceable, but Han disagrees. In the chapter The Nomos of the Earth, His view is that truth is at odds with 
transparency. Han further analyzes this concept in 2015's The Transparency Society. Truth is a narrative, but transparency is merely an accounting of something. The term "digital" itself references the finger, and counting... and counting does not a narrative make. We obsessively count our Likes and our shares and our followers, but fail to create the whole account of the matter. Relationships are narrative-driven and cannot be captured in a metric.

If truth is at one end of a spectrum and faith is at the other, Han suggests that an abundance of information is separating society from both. Information is "defactifying" society and "discrediting all faith" because it is removing any need for critical thinking and theorizing. If we have enough information, then we have enough. It should be unsettling to anyone in academia who traffics in theory that Han bravely suggests, "If enough data are available, no theory is needed." Is big data really the death of theory? Han's notable omission is any reference to Neil Postman's Informing Ourselves To Death, which arguably already described the swarm circa 1990, "But what started out as a liberating stream has turned into a deluge of chaos" and, "the tie between information and action has been severed."

The Recorded Life serves to remind us all that freedom is an illusion, and we are being traced every step of the way, with much of the information being self-contributed. Trust as a value in personal relationships is losing meaning because all information can be verified online. As his meditation on the digital state draws to a close, Han cautions us to recognize that the presence of digital brings us closer to a surveillance state, and closer to a society that can be controlled through psychopolitics.

Although In the Swarm could be interpreted only as a dark indictment of digital media's potential, Han correctly recognizes that digital continues to permeate our society beyond what we can comprehend and predict. The importance of digital communication as a shaping force in society is something that we should all be cognizant of, and Han's call to acknowledge the power of digital is a philosophy that should be carried into further research. Most of us are personally, socially and intellectually immersed in digital. Whether we like it or not, we are all part of the swarm.

\section{Cite this Review}

https://doi.org/10.20415/rhiz/032.r03

RHIZOMES ISSN 1555-9998 ^ 230 East Hall Bowling Green State University Bowling Green, OH 43403

Editors: Ellen Berry and Carol Siegel. Reviews editor: Craig J. Saper. Technical editor: Helen J Burgess 